\title{
BIODEGRADACIÓN ANAERÓBICA DE EFLUENTES DE UN FRIGORÍFICO DE PECES
}

Sogari ${ }^{1}$ Noemi, Vazquez ${ }^{2}$ Francisco, Gómez ${ }^{1}$ Carlos, Gassalla ${ }^{1}$ Alejandra

\section{Resumen}

Los grupos de investigación de la FaCENA, LABQUIAM y GER están desarrollando una tecnología para la implementación y operación de sistemas de generación de energía en base a la biodegradación de efluentes industriales en un frigorífico de peces ubicado en Bella Vista Corrientes. La instalación de un biodigestor contribuirá con la reducción de la contaminación de los efluentes de un frigorífico y eliminación los desechos del faenado de peces (pacú) por procesos biodegradables y transformarlos en energía útil.

Para cumplir con los objetivos del proyecto, primeramente se sometió el desecho de pescado obtenido en el frigorífico a estudios de laboratorio para obtener los parámetros químicos y físicos para conocer sus propiedades y capacidad de generar biogás. Los estudios y ensayos permitieron determinar las condiciones óptimas relacionadas con las proporciones de muestra de efluentes e inoculo, que evidencian la evolución de la degradación de la materia orgánica por un lado y la producción de biogás por otro.

\section{Palabras clave:}

Biodegradación efluentes, biogás, digestor

\section{Introducción}

La generación de los desechos orgánicos es una problemática ambiental mundial y en especial los que se generan en la industria cárnica.
La producción de desechos orgánicos y su acumulación en espacios inadecuados provocan, no solamente olores nauseabundos sino además, la degradación de estos residuos genera en su descomposición gas metano que es aportado al ambiente, siendo este un gas efecto invernadero con peores consecuencias que el CO2. Por lo tanto los desechos orgánicos generados en mataderos podrían ser considerados como una fuente de energía auxiliar, en lugar de solo un contaminante del ambiente.

Los principales constituyentes de contaminación de las aguas residuales de las plantas de procesamiento de carnes son sangre, restos de carne y grasas. Un uso adecuado de estos desechos, contribuiría a mejorar la protección del ambiente, ya que se evitaría que los desechos sean vertidos a cuerpos de aguas sin consideraciones sanitarias previas.

Los tratamientos aerobios y anaerobios constituyen las dos grandes opciones de depuración biológica. Sin embargo, el hecho de no necesitar aireación y la generación de biogás, que se puede utilizar en la misma planta con propósitos energéticos, hacen que la digestión anaerobia resulte mucho más favorable económicamente.

En la biodigestión anaerobia, los residuos orgánicos se degradan por procesos biológicos en ausencia de oxígeno. Al final del proceso, se produce en fase gaseosa una mezcla conocida como biogás (compuesta de un 50 a $60 \%$ de $\mathrm{CH} 4,30 \%$ de $\mathrm{CO} 2$, el resto constituyen vapor

${ }^{1}$ GER-FACENA-UNNE e-mail: noemisogari@gmail.com / ${ }^{2}$ LABQUIAM- FACENA-UNNE 
de agua, $\mathrm{H} 2 \mathrm{~S}, \mathrm{O} 2$ y trazas de otros compuestos). Además se obtiene un lodo residual como fertilizante enriquecido y un sobrenadante rico en nutrientes.

\section{Metodología}

El trabajo se llevó a cabo en el laboratorio, en gabinete y en el campo.

En el laboratorio se determinaron los parámetros químicos y físicos de los restos orgánicos del frigorífico para conocer sus propiedades y capacidad de generar biogás. Para ello se armaron cuatro

reactores del tipo batch, el cual se carga una sola vez en forma total y la descarga se efectúa una vez que se ha completado el proceso. Se ensayaron distintas mezclas en relación al sustrato-inóculo

Atendiendo a esto, la porción sólida de la mezcla utilizada estuvo constituida por las vísceras, en tanto que la líquida estuvo formada por la sangre y las aguas de lavado generadas durante la etapa de prolijado. Se midió la cantidad de biogás generado y acumulado durante 60 días. Las muestras mostraron distintos rendimientos en lo que atañe no solamente a la reducción de carga orgánica como también en cuanto a producción de biogás.

En gabinete se realizó el diseño del reactor que se usaría en el campo donde se continúan los análisis de la mezcla inoculo- residuo orgánico del frigorífico. El mismo consiste en un digestor de 200 litros de capacidad, conectado a un acumulador de gas. El mismo está dispuesto a campo abierto y trabaja bajo condiciones naturales.

Los resultados obtenidos en laboratorio y en campo fueron útiles para diseñar el sistema generador que se instalará en el frigorífico. Este consta de un prefermentador, un fermentador propiamente dicho con acumulador de gas y un depósito de residuos que serán usados como fertilizante orgánico.

\section{Conclusiones}

Con los resultados de los ensayos en laboratorio se inició la etapa de escala piloto para los efluentes industriales con matriz líquida del frigorífico de peces estableciendo las condiciones óptimas encontradas relacionadas con las proporciones de muestra de efluentes e inóculo y el seguimiento de los parámetros físico-químicos que evidencian la evolución de la degradación de la materia orgánica por un lado y la producción de biogás por otro. La etapa siguiente es la instalación del sistema generador de biogás en el frigorífico y la capacitación técnica de los operarios de la planta.

\section{Referencias}

Carothers R. Anaerobic digestión as a rural sanitation option. In: proceeding of a workshop on a training held in lobatse, Botswana. 14-20 august 1980. Otawa Canada. International Development research Centre. 34-40 pp.

Candelas-Ramírez, J.; Ramírez-Esquivel, G. Identificación y desarrollo de tecnología para proporcionar valor económico a los residuos sólidos del proceso de matanza en el rastro de saltillo. 1990. Coahuila, México. Oceanía. 190: 10-15.

Young, M.M. Digestores Anaerobios. Criterios de Selección, Diseño y Construcción. Instituto Nacional de Investigaciones sobre Recursos Bióticos. Xalapa, Veracruz. 1986. INIREB. (24): 30-34. 